\title{
Substitutional carbon reduction in SiGeC alloys grown by rapid thermal chemical vapor deposition
}

\author{
C. W. Liu, ${ }^{\text {a) }}$ Y. D. Tseng, and Y. S. Huang \\ Department of Electrical Engineering, National Taiwan University, 1, Roosevelt Road, Sec. 4, Taipei, \\ Taiwan, Republic of China
}

(Received 20 May 1999; accepted for publication 16 August 1999)

\begin{abstract}
The substitutional carbon reduction in $\mathrm{Si}_{1-x-y} \mathrm{Ge}_{x} \mathrm{C}_{y}$ strained layers, annealed at high temperatures, increases the compressive strain in the originally strain-compensated alloys. From the rocking curve simulation, the maximum amount of carbon reduction was below $0.9 \%$ for the various samples which were annealed below $1000{ }^{\circ} \mathrm{C}$ in the nitrogen flow. The interstitial silicon injection by thermal oxidation of the $\mathrm{Si}$ cap on the $\mathrm{Si}_{1-x-y} \mathrm{Ge}_{x} \mathrm{C}_{y}$ layer enhances the reduction of substitutional carbon to a concentration of $1.3 \%$. Oxidation of $\mathrm{Si}_{1-x-y} \mathrm{Ge}_{x} \mathrm{C}_{y}$ alloys yields a $\mathrm{Ge}$-enriched $\mathrm{Si}_{1-x} \mathrm{Ge}_{x}$ layer with the Ge concentration larger than the initial content, and the formation of $3 \mathrm{C}$ silicon carbide precipitate is observed by the Fourier transform infrared spectroscopy. (C) 1999 American Institute of Physics. [S0003-6951(99)04641-0]
\end{abstract}

Recently, there has been impressive progress in the growth $^{1,2}$ and characterization ${ }^{3-5}$ of $\mathrm{Si}_{1-x-y} \mathrm{Ge}_{x} \mathrm{C}_{y}$ alloys, which offer great flexibility to tailor the strain and the electronic properties of group IV heterostructures. ${ }^{6,7}$ The substitutional incorporation of $\mathrm{C}$ can compensate the compressive strain of $\mathrm{Si}_{1-x} \mathrm{Ge}_{x}$ layers grown on $\mathrm{Si}$ substrates and suppress the boron outdiffusion in the base of $\mathrm{Si} / \mathrm{Si}_{1-x-y} \mathrm{Ge}_{x} \mathrm{C}_{y} / \mathrm{Si}$ heterojunction bipolar transistors. ${ }^{7}$ However, the reduction of substitutional carbon in $\mathrm{Si}_{1-x-y} \mathrm{Ge}_{x} \mathrm{C}_{y}$ alloys during high temperature processing limits the applications of this material. The study ${ }^{8}$ on thick 80-160 nm $\mathrm{Si}_{1-x-y} \mathrm{Ge}_{x} \mathrm{C}_{y}$ samples with $x=0$ or 0.11 and $y=0.005$ and 0.01 grown by rapid thermal chemical vapor deposition (RTCVD) showed that the reduction of substitional carbon at $1000-1130^{\circ} \mathrm{C}$ was caused by $3 \mathrm{C}$ silicon carbide precipitates. The study ${ }^{9}$ on thick $230 \mathrm{~nm}$ $\mathrm{Si}_{0.9855} \mathrm{C}_{0.0145}$ grown on molecular beam epitaxy also showed that the carbon related defects or silicon carbide precipitates were responsible for the strain-relieving process. Both studies conclude that the width of carbon profiles does not change during the annealing process. The study ${ }^{10}$ on thin $\mathrm{Si}_{1-x-y} \mathrm{Ge}_{x} \mathrm{C}_{y}(\sim 20 \mathrm{~nm})$ samples showed the reduction of substitutional carbon increased the compressive strain in the epilayer and thus yields misfit dislocation relaxation, while the film thickness is below the critical thickness. In this letter, we report the quantitative analysis of the substitutional carbon reduction in the $\mathrm{Si}_{1-x-y} \mathrm{Ge}_{x} \mathrm{C}_{y}$ alloys with various sample structures. The substitutional carbon reduction can be enhanced by the interstitial silicon injection.

The $\mathrm{Si}_{1-x-y} \mathrm{Ge}_{x} \mathrm{C}_{y}$ single quantum wells were grown on $\mathrm{Si}\langle 100\rangle$ substrates by RTCVD. The $\mathrm{Si}_{1-x-y} \mathrm{Ge}_{x} \mathrm{C}_{y}$ layers with carbon content less than 0.012 were grown at $625^{\circ} \mathrm{C}$ using methylsilane as the $\mathrm{C}$ source. For higher carbon content samples $(y=0.022)$, the growth temperature was $550{ }^{\circ} \mathrm{C}$. The higher substitutional carbon incorporation at lower temperature is consistent with the previous report. ${ }^{11}$ The growth pressure was 6 Torr. The gas flows were 3 slpm

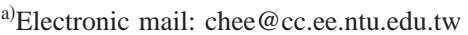

for a hydrogen carrier, $26 \mathrm{sccm}$ for dichlorosilane, and 0.8 sccm for germane. The Si cap layers for less-carbon-content samples $(y \leqslant 0.12)$ were grown at $700^{\circ} \mathrm{C}$, using a $26 \mathrm{sccm}$ dichlorosilane flow and a 3 slpm hydrogen flow. The Si caps of high-carbon content samples $(y=0.022)$ were grown at $550{ }^{\circ} \mathrm{C}$, using a $4 \mathrm{sccm}$ silane flow and a 3 slpm hydrogen flow. The Ge fraction and thickness of $\mathrm{Si}_{1-x} \mathrm{Ge}_{x}$ was extracted by fitting $\mathrm{x}$-ray rocking curves. The details of the $\mathrm{Si}_{1-x-y} \mathrm{Ge}_{x} \mathrm{C}_{y}$ growth can be found in Ref. 2. As small amounts of methylsilane were added to the source gases, we observed a shift in the (400) x-ray diffraction peak of the resulting $\mathrm{Si}_{1-x-y} \mathrm{Ge}_{x} \mathrm{C}_{y}$ layers away from that of a similar layer without addition of methylsilane. Vegard's law with a compensation ratio of $1 \% \mathrm{C}$ to $8.3 \% \mathrm{Ge}$ was used ${ }^{1,2}$ to estimate the carbon concentration in alloys. The carbon content was obtained from the shift of the (400) peak by assuming the Ge concentration was unchanged as methylsilane was added. The thickness of the as-grown $\mathrm{Si}_{1-x-y} \mathrm{Ge}_{x} \mathrm{C}_{y}$ quantum well was also extracted by fitting the rocking curves, which has been calibrated by Auger electron spectroscopy depth profiles on thick samples. Secondary ion mass spectroscopy (SIMS) also has confirmed flat $\mathrm{C}$ profiles, and that Ge concentration was unchanged by adding the methylsilane on calibration samples.

Quantum well structures were investigated in this study. The nominal thickness of the Si caps was about 60 and 30 $\mathrm{nm}$ for $625^{\circ} \mathrm{C}$-grown $\mathrm{Si}_{1-x-y} \mathrm{Ge}_{x} \mathrm{C}_{y}$ layers and $550{ }^{\circ} \mathrm{C}$ grown $\mathrm{Si}_{1-x-y} \mathrm{Ge}_{x} \mathrm{C}_{y}$ layers, respectively. All as-grown samples are pseudomorphic and fully strained due to the low temperature growth. No defect was observed in these asgrown films after defect etching, using four parts of $49 \% \mathrm{HF}$ and five parts of $0.3 \mathrm{M} \mathrm{CrO}_{3}$.

To study the substitutional carbon reduction of the $\mathrm{Si} / \mathrm{Si}_{1-x-y} \mathrm{Ge}_{x} \mathrm{C}_{y} / \mathrm{Si}$ quantum wells, the x-ray rocking curves from as-grown and annealed samples were measured. The samples were annealed at temperature from 800 to $1000{ }^{\circ} \mathrm{C}$ in nitrogen. To avoid the nonuniformity on $100 \mathrm{~mm}$ wafer, a cumulative annealing scheme is adopted. In other words, the annealing treatment at different temperatures was 


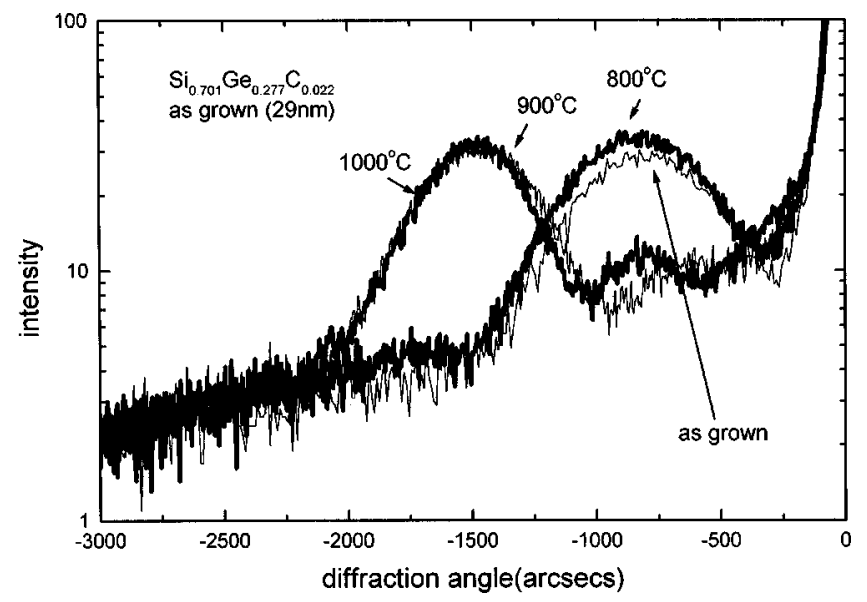

FIG. 1. The high-resolution x-ray diffraction spectra of a $29 \mathrm{~nm}$ $\mathrm{Si} / \mathrm{Si}_{0.701} \mathrm{Ge}_{0.277} \mathrm{C}_{0.022} / \mathrm{Si}$ quantum wells. The annealing time is $2 \mathrm{~h}$ for each temperature.

performed on the same piece of samples. The peaks of the (400) x-ray rocking curves for a $29 \mathrm{~nm}$ $\mathrm{Si} / \mathrm{Si}_{0.701} \mathrm{Ge}_{0.277} \mathrm{C}_{0.022} / \mathrm{Si}$ quantum well sample shifts away from Si peak continuously (Fig. 1), when the sample was annealed for $2 \mathrm{~h}$ from 800 to $1000^{\circ} \mathrm{C}$. The slight shift of $800^{\circ} \mathrm{C}$ annealing process indicates the structure starts to relax. The low growth temperature of this sample may be responsible for this, since $625^{\circ} \mathrm{C}$-grown samples are stable at $800{ }^{\circ} \mathrm{C}$ annealing for $2 \mathrm{~h}^{10}$ From the positions of the (400) diffraction peaks, the vertical lattice constant can be obtained for various samples (Fig. 2). The $37 \mathrm{~nm} \mathrm{Si} i_{0.723} \mathrm{Ge}_{0.277}$ and $20 \mathrm{~nm} \mathrm{Si} i_{0.77} \mathrm{Ge}_{0.23}$ control samples reveal a continuous decrease of vertical lattice constant for the $2 \mathrm{~h}$ annealing from 800 to $1000{ }^{\circ} \mathrm{C}$. This is due to the Ge out-diffusion and misfit dislocation formation. ${ }^{10}$ The annealing is performed in the ultrapure nitrogen flow. For the $18 \mathrm{~nm} \mathrm{Si}_{0.762} \mathrm{Ge}_{0.23} \mathrm{C}_{0.008}$ sample, the vertical lattice constant drops slightly for the $2 \mathrm{~h}$ annealing from 800 to $1000^{\circ} \mathrm{C}$. For the $18 \mathrm{~nm}$ $\mathrm{Si}_{0.758} \mathrm{Ge}_{0.23} \mathrm{C}_{0.012}$ sample, the vertical lattice constant decreases at $900{ }^{\circ} \mathrm{C}$ annealing for $2 \mathrm{~h}$, but increases for the $2 \mathrm{~h}$ annealing from 900 to $1000^{\circ} \mathrm{C}$. For the thick $29 \mathrm{~nm}$ $\mathrm{Si}_{0.701} \mathrm{Ge}_{0.277} \mathrm{C}_{0.022}$ sample, the vertical lattice constant increases for the $2 \mathrm{~h}$ annealing from 800 to $1000^{\circ} \mathrm{C}$. This

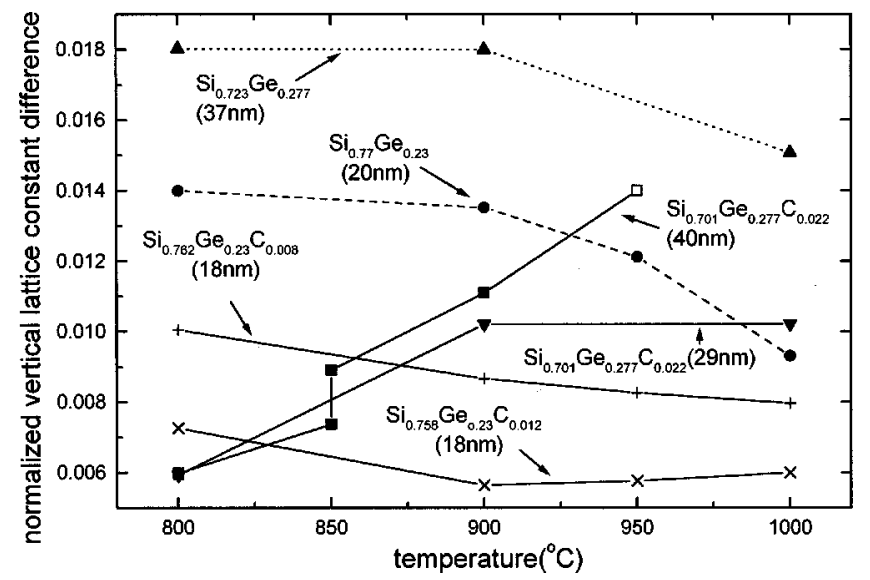

FIG. 2. The difference between vertical lattice constant of $\mathrm{Si}_{1-x-y} \mathrm{Ge}_{x} \mathrm{C}_{y}$ and $\mathrm{Si}$ substrate normalized with respect to $\mathrm{Si}$ lattice constant at different annealing temperature. Solid symbols indicate the annealing in nitrogen. The empty square indicates the oxidation.

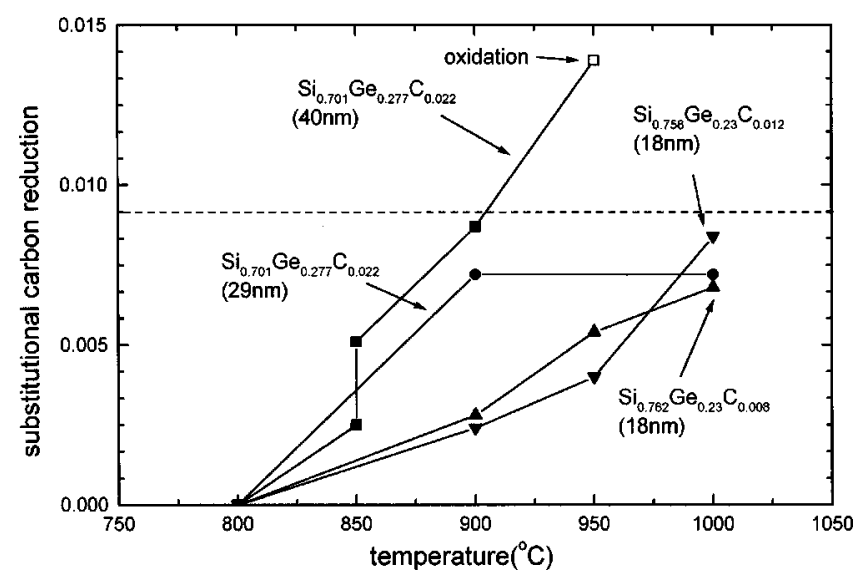

FIG. 3. The concentration of the substitutional carbon reduction for various $\mathrm{Si}_{1-x-y} \mathrm{Ge}_{x} \mathrm{C}_{y}$ samples processed at different temperature. The empty square indicates the oxidation.

complicated behavior of $\mathrm{Si}_{1-x-y} \mathrm{Ge}_{x} \mathrm{C}_{y}$ relaxation is most likely due to the combined effects of Ge out-diffusion, misfit dislocation formation, and the reduction of substitutional carbon. The Ge out-diffusion and misfit dislocation formation increase the vertical lattice constant, but the reduction of substitutional carbon decreases the vertical lattice constant. For thin samples, the Ge out-diffusion is important to change the vertical lattice constant, since the diffusion can lower the average Ge concentration more significantly, as compared to thick samples. However, the effect of substitutional carbon reduction on the vertical lattice is more pronounced in thick samples. To obtain the amount of substitutional carbon, the box profile of substitutional $\mathrm{C}$ distribution is assumed to fit the (400) diffraction rocking curves. From the secondary ion mass spectroscopy (SIMS), the width of carbon profile is unchanged. ${ }^{8,9}$ The Ge profile is taken from the solution of one-dimensional interdiffusion equation. ${ }^{12}$ The relaxation of misfit dislocation is determined by the (422) asymmetrical reflex. The substitutional carbon content in $\mathrm{Si}_{1-x-y} \mathrm{Ge}_{x} \mathrm{C}_{y}$ epilayers can be obtained. The details can be found in Refs. 10 and 13.

Figure 3 shows the amount of substitutional carbon reduction for various samples at different annealing temperatures. It is clear that the substitutional carbon reduction increases as the temperature increases for all the samples. The reduction of substitutional carbon reaches a maximum amount of 0.009 for all these samples. A $40 \mathrm{~nm}$ $\mathrm{Si}_{0.701} \mathrm{Ge}_{0.277} \mathrm{C}_{0.022}$ sample was continuously annealed from 800 to $900{ }^{\circ} \mathrm{C}$ for $2 \mathrm{~h}$ in the nitrogen flow. The vertical lattice constant (Fig. 2) and the substitutional carbon reduction (Fig. 3 ) of this sample increases for each annealing step. For the annealing at $850^{\circ} \mathrm{C}$, this sample was annealed two times. The vertical lattice constant of the $40 \mathrm{~nm} \mathrm{Si}_{0.701} \mathrm{Ge}_{0.277} \mathrm{C}_{0.022}$ sample continues to increase after the second annealing step at $850{ }^{\circ} \mathrm{C}$. This indicated substitutional carbon reduction does not reach thermal equilibrium at the annealing time. Similar results have been reported. ${ }^{9}$ To further investigate the substitutional carbon reduction behavior, we performed a $2 \mathrm{~h}$ oxidation process at $950^{\circ} \mathrm{C}$ on the $40 \mathrm{~nm}$ $\mathrm{Si}_{0.701} \mathrm{Ge}_{0.277} \mathrm{C}_{0.022}$ sample. This oxidizes the $3 \mathrm{~nm} \mathrm{Si}$ cap and injects interstitial $\mathrm{Si}$ into the $\mathrm{Si}_{0.701} \mathrm{Ge}_{0.277} \mathrm{C}_{0.022}$ alloys, the vertical lattice constant continues to increase as determined Copyright @2001. All Rights Reserved. 


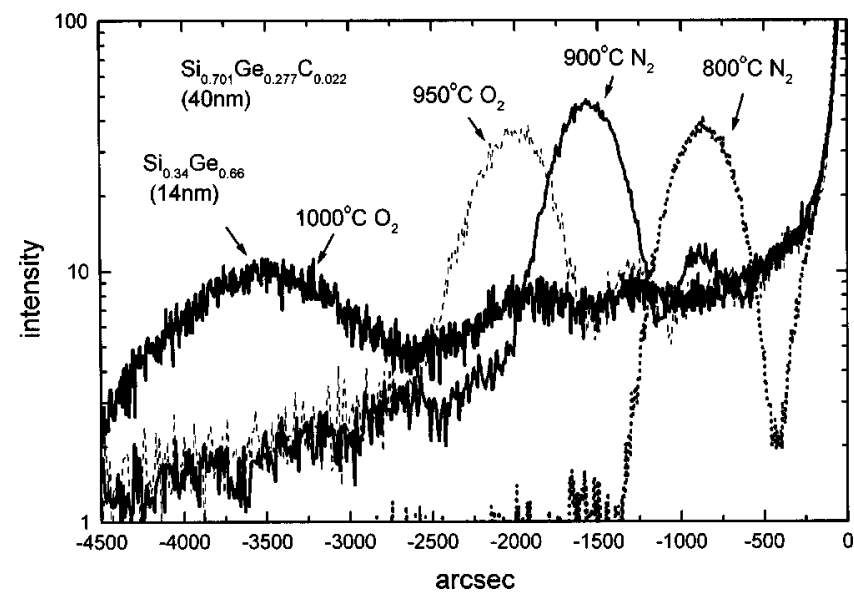

FIG. 4. The high-resolution x-ray diffraction spectra of a $40 \mathrm{~nm}$ $\mathrm{Si} / \mathrm{Si}_{0.701} \mathrm{Ge}_{0.277} \mathrm{C}_{0.022} / \mathrm{Si}$ quantum well.

from the (400) rocking curves (Fig. 4) and the substitutional carbon reduction increases from 0.009 to 0.013 . This indicated that the interstitial silicon injection can kick out substitutional carbon and reduce the concentration of the substitutional carbon. Please note that the concentration of interstitial silicon at thermal equilibrium is very low $\left(10^{13} \mathrm{~cm}^{-3}\right.$ at $\left.1000^{\circ} \mathrm{C}\right){ }^{14}$ The interstitial silicon cannot be the sole source of the substitutional carbon reduction at thermal equilibrium. The substitutional carbon may jump out of the lattice site with its own kinetics, but it is clear that the interstitial silicon can enhance this process.

After further oxidation of the $\mathrm{Si}_{0.701} \mathrm{Ge}_{0.277} \mathrm{C}_{0.022}$ sample at $1000^{\circ} \mathrm{C}$ for $2 \mathrm{~h}$, the oxidation reaches the $\mathrm{Si}_{0.701} \mathrm{Ge}_{0.277} \mathrm{C}_{0.022}$ layer, and the layer thickness decreases to 14 from $40 \mathrm{~nm}$ estimated from the (400) rocking curves (Fig. 4). The Ge content in this layer becomes approximately 0.66 , assuming the negligible substitutional carbon content, and the layer was completely relaxed, obtained from the (422) reflex. The Ge content will be even higher, if there is some residual substitutional carbon. This severe Ge enrichment effect was not observed in the pure $\mathrm{Si}_{1-x} \mathrm{Ge}_{x}$ control samples. The oxidation of $\mathrm{Si}_{1-x} \mathrm{Ge}_{x}$ alloys results in the Ge pile-up at the oxide/ $/ \mathrm{Si}_{1-x} \mathrm{Ge}_{x}$ interface. ${ }^{15}$ The Ge diffusion into $\mathrm{Si}_{1-x-y} \mathrm{Ge}_{x}$ underneath may be enhanced by the interstitialcarbon-related defect ${ }^{10}$ and yields a Ge-enriched layer. The Fourier transform infrared spectrum of the $1000{ }^{\circ} \mathrm{C}$-oxidized $\mathrm{Si}_{0.701} \mathrm{Ge}_{0.277} \mathrm{C}_{0.022}$ sample with reference to the as-grown sample reveals a decrease of $600 \mathrm{~cm}^{-1}$ substitutional carbon vibration peak, and an increases of silicon-carbide-like absorption peak, similar to the $3 \mathrm{C}$ silicon carbide absorption spectrum (Fig. 5). ${ }^{16}$

The quantitative analysis of substitutional carbon reduction in $\mathrm{Si}_{1-x-y} \mathrm{Ge}_{x} \mathrm{C}_{y}$ at high temperature process was performed. A maximum reduction of 0.009 was observed for

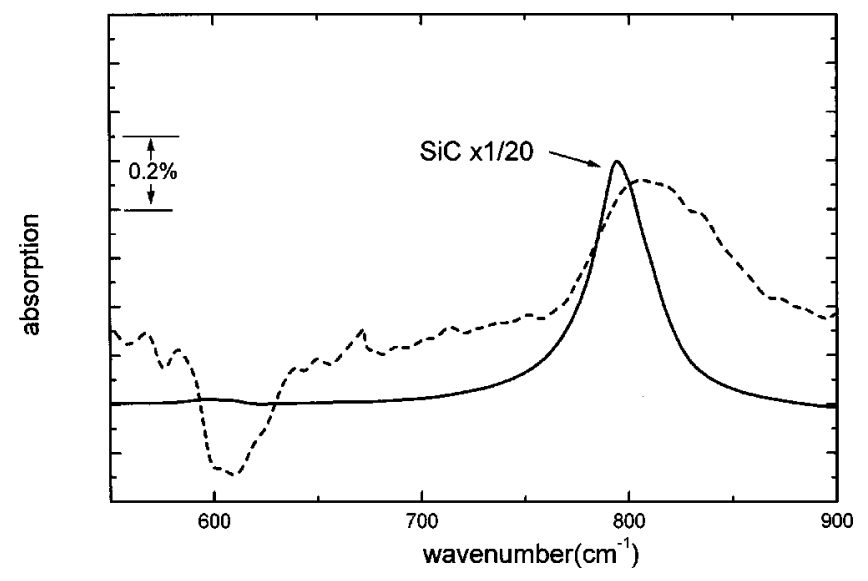

FIG. 5. The Fourier transform infrared spectrum of a $40 \mathrm{~nm}$ $\mathrm{Si}_{0.701} \mathrm{Ge}_{0.277} \mathrm{C}_{0.022}$ sample, oxidized at $1000{ }^{\circ} \mathrm{C}$ for $2 \mathrm{~h}$. The spectrum of $3 \mathrm{C}$ silicon carbide is also shown for reference.

various samples for annealing below $1000{ }^{\circ} \mathrm{C}$ in nitrogen, but kinetics of the substitutional carbon reduction is not clear. The interstitial Si injection can enhance the substitutional carbon reduction to 0.013 . The oxidation of $\mathrm{Si}_{1-x-y} \mathrm{Ge}_{x} \mathrm{C}_{y}$ can inject the Ge into the unoxidized layer and can form a Ge-enriched layer.

The assistance of x-ray diffraction measurement by Professor M. Y. Chern, National Taiwan University is highly appreciated. The authors would also like to thank the group of Professor James Sturm at Princeton University for supplying the samples. This work is supported by National Science Council (NSC 88-2218-E-002-004).

${ }^{1}$ J. L. Regolini, F. Gisbert, G. Dolino, and P. Boucaud, Mater. Lett. 18, 57 (1993).

${ }^{2}$ C. W. Liu, A. St. Amour, J. C. Sturm, Y. R. J. Lacroix, M. L. W. Thewalt, C. W. Magee, and D. Eaglesham, J. Appl. Phys. 80, 3043 (1996).

${ }^{3}$ P. Boucaud, C. Francis, F. H. Julien, J.-M. Lourtioz, D. Bouchier, S. Bodnar, B. Lambert, and J. L. Regolini, Appl. Phys. Lett. 64, 875 (1994).

${ }^{4}$ A. St. Amour, C. W. Liu, J. C. Sturm, Y. Lacroix, and M. L. W. Thewalt, Appl. Phys. Lett. 67, 3915 (1995).

${ }^{5}$ C. Y. Lin and C. W. Liu, Appl. Phys. Lett. 80, 1441 (1997).

${ }^{6}$ L. D. Lanzerotti, A. St. Amour, C. W. Liu, J. C. Sturm, J. K. Watanabe, and N. D. Theodore, IEEE Electron Device Lett. 17, 334 (1996).

${ }^{7}$ I. M. Anteney, G. Lippert, P. Ashburn, H. J. Osten, B. Heinemann, G. J. Parker, and D. Knoll, IEEE Electron Device Lett. 20, 116 (1999).

${ }^{8}$ P. Warren, J. Mi, F. Overney, and M. Dutoit, J. Cryst. Growth 157, 414 (1995).

${ }^{9}$ H. J. Osten, D. Endisch, E. Bugiel, B. Dietrich, G. G. Fischer, M. Kim, D. Kruger, and P. Zaumseil, Semicond. Sci. Technol. 11, 1678 (1996).

${ }^{10}$ C. W. Liu, Y. D. Tseng, M. Y. Chern, C. L. Chang, and J. C. Sturm, J. Appl. Phys. 85, 2124 (1999).

${ }^{11}$ H. J. Osten, J. Griesche, and S. Scalese, Appl. Phys. Lett. 74, 836 (1999).

${ }^{12}$ P. Boucaud, L. Wu, C. Guedj, F. H. Julien, I. Sajnes, Y. Campidelli, and L. Garchery, J. Appl. Phys. 80, 1414 (1996).

${ }^{13}$ C. W. Liu, Y. D. Tseng, and M. Y. Chern (unpublished).

${ }^{14}$ T. Sinno, Z. K. Jiang, and R. A. Brown, Appl. Phys. Lett. 68, 3028 (1996).

${ }^{15}$ P.-E. Hellberg, S.-L. Zhang, F. M. d'Heurle, and C. S. Petersson, J. Appl. Phys. 82, 5773 (1997).

${ }^{16}$ C. W. Liu and J. C. Sturm, J. Appl. Phys. 82, 4558 (1997). 